\title{
Research on Song Dynasty Literature and Communication
}

\author{
Hongjuan Luo \\ Liaocheng University Dongchang College, Liaocheng, Shandong Province, 252000 China. \\ xiaopang5125@126.com
}

Keywords: Song literature, Research methods, Dissemination, Media.

\begin{abstract}
As a unique style of the Song Dynasty literature, poetry was developed and expanded in the Song Dynasty and became a prominent symbol of this period. The prosperity of literature is in the eliminators, receivers, communication media, dissemination of ecological environment and other factors Generated under joint action. This article examines in detail the method of dissemination of the Song Dynasty literature, and uses Shandong poets as research features to study academic achievements in literature and communication and apply the theory of communication to the field of literary studies.
\end{abstract}

\section{Introduction}

The literature of the Song Dynasty as a generation of literary literature is even more important in the history of culture. Formed in the Sui and Tang Dynasties, to the two Songs and flourished, in the history of Chinese poetry, the only thing worthy of the Tang poetry is the literature. The poems are large in the Northern Song Dynasty, deep in the Southern Song Dynasty, or unrestrained, or graceful, or indignant, or heroic, or ethereal, or lingering. The song does its best and the word does its best. It can be said that Song dynasty cultural creators used the literary genre of the word to reach the point of becoming a culmination, and that the creation of descendants of cultural writers rarely exceeds the scope of literature. There are still more than 20,000 literary works in existence, with various styles and bodies [1]. Literary works have had a profound influence on later generations, especially in the Qing Dynasty.

In addition to poetry, words, and prose, the Song Dynasty's literature in the Song Dynasty had far more progress than the previous generation in colloquialism, opera, and other popular literature. The subject matter of the Song dynasty was extensive. It reflected the social life of the time more extensively than the literary works of the past [2]. In the history of Chinese fiction, the novel in the Song Dynasty opened up a new era of fiction, which directly influenced the birth of the Ming and Qing dynasties. The long chapter novels with the theme of history in the Ming and Qing Dynasties were the inheritance and development of the long storybooks of the Song Dynasty. In addition, the Song dynasty storybook also provided a lot of themes for Yuan and Ming dramas. The drama also gradually matured in the Song Dynasty. Song operas originated from the Tang Dynasty military participation play, which had a direct impact on the Yuan Zaju in content and form [3]. The prosperity of the Song Dynasty literature also promoted the prosperity of the Song Dynasty literary criticism. The theory of the creation of individual literature in the Song Dynasty has made considerable progress compared to the previous generation. The poetry, words, commentaries, and prefaces of the Song Dynasty are endless [4].

\section{Reasons for the Rapid Development of Song Culture}

Song Dynasty literature and Song Dynasty culture are able to achieve such glorious achievements, the reasons are also many, mainly the development and progress of the Song Dynasty literature dissemination, literature cannot be separated from the dissemination of the media, the media is not only a tool for the spread of literature, but also It is also an important dimension of literature itself. The media revolution in different periods influences the development and evolution of literature. The 
prosperity of the media in Song Dynasty promoted the prosperity of literature and the establishment of poetry "culture", which helped to promote the success of the Song Dynasty poetry innovation movement, promoted the rise of colloquial novels in the Song Dynasty, and played a role in the formation and growth of the Song literary school. Promote the role of aid [5]. The fact that the prosperity of the media promoted the transformation of the Song Dynasty's literature has eloquently proved that the history of the development of literature is also the evolutionary history of the literary media [6].

Just as science and technology are primary productivity, advanced media technologies are also important cultural productivity. The prosperity of the printing press of the Song Dynasty not only enabled the Song Dynasty court to obtain a powerful tool for disseminating imperial power culture, but also enabled the scholars of the Song Dynasty to gain a tool for understanding literature, creating literature, and disseminating literature. As a media production technology[7], printing reduces the threshold of literary dissemination, expands the scope of literary dissemination, increases the productivity of literature, enhances the influence of literature, and leads to ordinary people, which in turn has led to the rise of popular literature. From this we can see that the media flourishing in the Song Dynasty made immortal contributions to the spread of ancient Chinese literature. The reason that the Song Dynasty literature can achieve such brilliant achievements is that it has reached the broader world such as the city well, and is closely related to the flourishing printing media of the Song Dynasty [8].

\section{The Research Methods of Song Communication}

\subsection{Definition of Communication in Ancient Chinese Literature.}

Through the dissemination of the main body, the dissemination of the environment, the mode of transmission, the dissemination of content, the dissemination of the object, the dissemination effect In accordance with the general principles of socialized production, literary activities also include basic links such as production, circulation, consumption, and reproduction. The so-called literary communication includes circulate links such as rap, transmission, editing, compilation, publication, printing, sale, and reading. It is the link that sustains the basic elements of authors, works, and readers. In real life, literary works are bound to make sense through readers' reading. It is also impossible for the author to write for the sake of writing. The work cannot be forever estranged. It must break through the obstacles of space and be broadcast to all people, but it must also be transmitted to the world through time. Literature can only enter the dissemination process and reach the hands of the readers. The significance and function of literature itself can be realized.

The communication media is one of the four major elements of literary dissemination. It is the bridge and link between the author and the reader. The printing media of the Song Dynasty plays a decisive role in the dissemination of literature. First of all, this is because the transmission of literary texts is inseparable from the media. Writers' writing is also materialized as media. Literary texts can be issued, circulated, consumed and accepted. The literary medium is also the first link that leads readers into literary communication. It can be said that there is no literature without media. Secondly, the role of the media in literature is not only the external material transmission channel of literature, but also one of the important constituent dimensions of literature. It not only realizes the material transmission of literary information, but also gives meaning and rhetorical effect to literature. Subtle and important influence. The revolution of the media is closely linked with the development of literature. The new media is constantly expanding the human sense organs. Literature also adjusts its own form to adapt to the new media. The development of the Song Dynasty literature is also the same.

\subsection{The Environment of Song Communication.}

According to the theory of communication, communication is "the transmission of social information or the operation of social information systems." Human social communication is carried out in certain social relations and is a manifestation of certain social relations. Environmental factors, as an aspect of social relations, are the basis and conditions of communication activities. Information 
dissemination cannot be separated from the concrete environment in which information deliminators and information receivers coexist. Social communication is an extremely complicated process. Every communication activity and each communication process is not only restricted by its internal mechanism, but also influenced by the external environment and conditions. It is also the basic reason for everything. Poems and words were prolific and developed during the 300 years of the Song dynasty and were closely related to the social environment that they produced and spread.

\subsection{The Way of Communication of Song Dynasty Literature.}

(1) Interactive communication of gifts, singing and singing among people.

The communion of singing and gifting is the main form of dissemination within the literati circle. It is also a common form of dissemination and acceptance of ancient literature. Especially in ancient times where printing was not yet well developed, large-scale printing and dissemination is unlikely, and therefore only It can be circulated among like-minded people in the form of gifts and transmissions. In the Song Dynasty, rewards for cultural writers were also frequent, and followers received rewards after receiving rewards. From the point of view of communication, they were quick feedback. In this way, it is easy to form a literary school with almost the same style. In singing and gift giving, sing and rhyme are the more frequent cultural life of cultural creators. As a mode of communication, they are more direct and easier to form than group gifts.

(2) Verbal communication with song and dance actors as the medium of communication.

As a kind of music literary works, the most important feature of the word is that it is better than music. That is to say, the voice of the song is transmitted, the orchestral music is broadcast, and the words are matched with musical scores and spread through musical instruments accompanying or performing. This kind of dissemination method has a strong real-time nature and is the most convenient, general, and wide-ranging dissemination method before mass media. There are two types of verbal communication: instant communication and diachronic communication. Dynamic real-time communication is the product of the early satisfaction of songs. The game function and entertainment function of wine Qing Huan are the main functions of words. As we all know, words in the Song Dynasty can be regarded as the most fashionable and popular styles at that time. From emperors to deacons, down to the peddler, everyone likes to listen to lyrics. These female poets and female cultural creators came from different strata, from the Queen to the song and dance actor. Among them were Li Qingzhao, (circa 1084-1151) and Zhangqiu (now Shandong Zhangqiu). Southern song female culture creator. "The $\mathrm{Yi}$ and Settlement" and "Yi and $\mathrm{Ci}$ " have been scattered. Later generations have "Suiyu Ci." Today's collection has "Li Qingzhao Collection." Li Qingzhao's collection was printed at the time. "Huang Sheng's "The Selection of Flowers and Poems" said there are 3 volumes of "Sui Yu Ci"."Song Shi Yi Wen Zhi" contains 7 volumes of "The Yi and Settlers' Collection" and 6 volumes of "Yi and $\mathrm{Ci}$ ". It has not been passed for a long time. The existing poems and collections are compiled by later generations. The four ink prints have a volume of, and Li Wen's "Ruiyu Set" has 5 volumes. However, there are many fakes in this collection. There are 60 "Suiyu Ci" in Zhao Qianli's "College Song Jin Yuan Ren Ci". There is a new discovery of Li Qingzhao in the present man Kong Fanli's Supplement to the Whole Text. Wang Zhongwen has Li Qingzhao's Anthology, and the People's Literature Publishing House has a printed copy. 


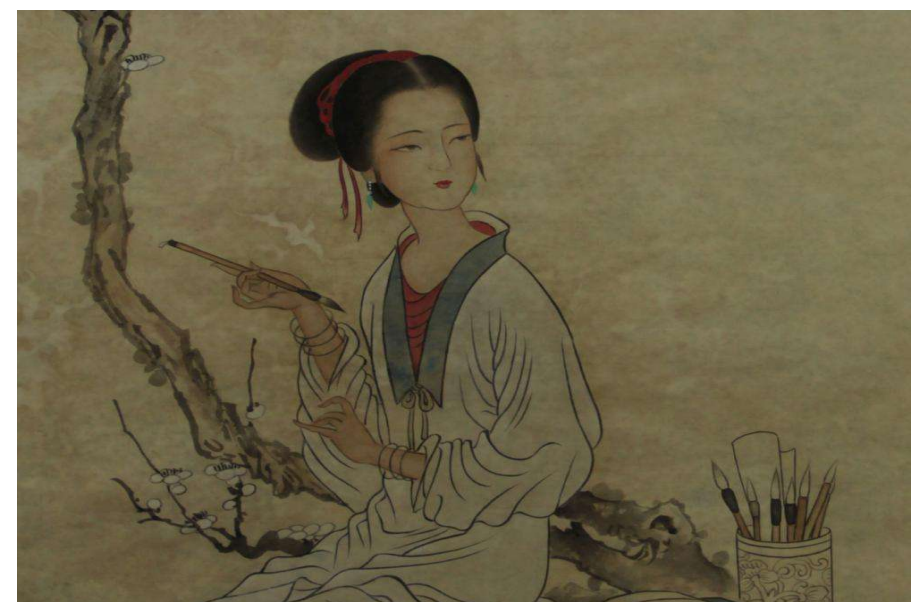

Fig. 1 Song Dynasty female writer from the hometown of Shandong - Li Qingzhao

\subsection{The Power of Communication in Song Dynasty Literature.}

Communicators and recipients are two important factors in communication. In the Song Dynasty, which was based on interpersonal communication and group communication, the word authors were often the main propagators. The author controls the direction and content of the dissemination. From the point of view of modern communication, it is "the gatekeeper." The receiver is the end of literary dissemination. The dissemination of literary works ultimately acts on the reader's audience. Only when the recipient accepts it can the value of the work be realized. The value orientation of the recipient also has an important influence on the dissemination of literary works. The trend of commercialization of literature has two main influences and effects on the development of Song literature. The first is to create a group of "professional" authors who make poetry and writing a living. The second is to accelerate the dissemination and consumption of literary works. The interaction between dissemination and acceptance of these two dimensions is an important driving force for the dissemination of literature. For example, Wang Shuo from Shandong Province is a professional culture creator who vigorously wrote words in the history of the Song dynasty. He is also the first cultural creator in the history of Chinese literature who is good at using communication methods and making himself successful. Wang Wei was the pioneer of the Northern Song Dynasty poetry and literary innovation movement. Literature Han Yu, Liu Zongyuan, poetry Du Fu and Bai Juyi reflected social reality and the style was fresh and easy. The existence of only one word reflects the political ambition of the author's active use of the world. He is the author of "Little Cattle Collection" and "Five-Year History. Wang Hao can write poetry when he is nine.

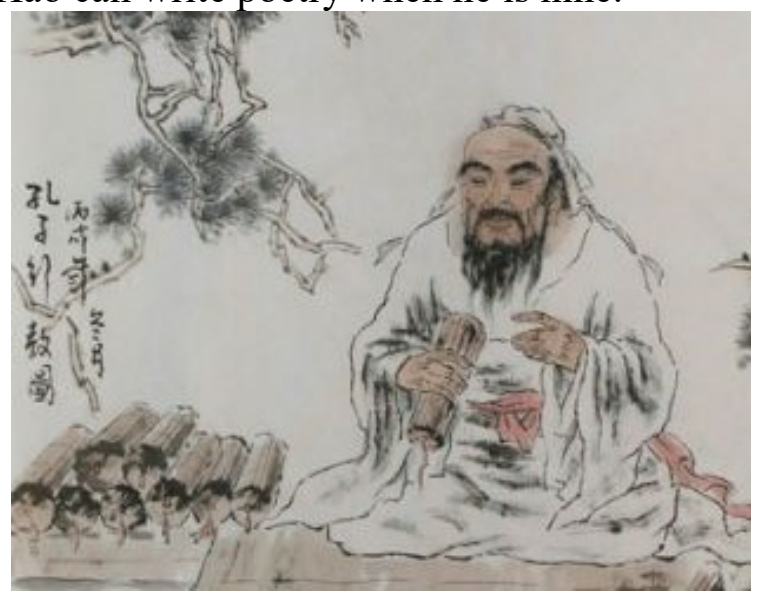

Fig. 2 The pioneer of the Northern Song Wen innovation movement

\subsection{The Communication Effect of Song Dynasty Literature.}

The communication effect refers to the change of the audience's ideas, behaviors, etc. as the information sent by the communicator is transmitted to the audience through the media. The dissemination effect is the effective result of many factors such as the communicator, the media, the object of communication, and the dissemination skills. The "effective result" here refers narrowly to 
the degree to which an actor's behavior achieves its intention or goal; in the broad sense it refers to the objective result of this behavior, including all effects on the actual role of the other person and the surrounding society. And consequences. Therefore, the effect of communication has twofold meanings. First, it refers to the change in mentality, attitude and behavior caused by the persuasive communicative behavior in the recipient, which mainly refers to persuasive sexual transmission; secondly, it refers to the spread. The overall impact of the activity on the recipient and the society and the overall result, whether the effect is intentional or unintentional, direct or indirect, apparent or potential. The effect of the word transmission in the Song Dynasty was mainly in the latter. The effect of words can be expressed on the cognitive level of people, causing changes in people's knowledge and knowledge structure; it can manifest on the psychological level of people, cause people's ideas or value system to cause changes in emotions or feelings, and can also express at the action level, there are changes in words and actions.

\subsection{The Cultural Value of Song Dynasty Literature.}

The dissemination of Song literature promoted the combination of elegant culture and popular culture, leading to the prosperity and development of the word. The development of words as one of the superstructures is compatible with social and economic conditions. The secularization features of the Song Dynasty society are deeply and prominently expressed in the process of word spread. Secularization has become the main form of social culture in the Song Dynasty. After the Song Dynasty was established in $960 \mathrm{AD}$, the social economy developed at a faster rate, and the social wealth and production level gradually surpassed the history of the Han and Tang dynasties. The three years of the Northern Song Dynasty (1019) in the country's household registration system separated the urban residences of Goofing and rural residents for the first time, reflecting the feudal society's later development stage. The significance of the urban economy in the entire national economy has been highlighted. Populations in the cities with a population of 100,000 or even millions continue to emerge. For example, the population of Kaifeng and Liana in the capital of the Song Dynasty exceeds one million. Among such a dense population, apart from the royal family and the literati and banned soldiers, the vast majority are handicrafts men, merchant peddlers, and urban residents who can be classified as "citizens." The rise of the Chinese people's social stratum will inevitably produce cultural needs that suit the characteristics of their lives. This culture is because its producers and consumers are "secular" citizens. Their status, job vocation, cultural education, and ideological interests are different from those of orthodox scholars. Therefore, they have a "custom". The style and taste. On behalf of the writer Xin Qiji (1140 1207) word Youan, No. Jiacuan, Li City (now Jinan, Shandong) people. South literati. There is a "jiaxuan word." Wang Shuo was born in Shandong Dongping. Yuan Dynasty agronomist and improper of typography. The "Agricultural Book" was handed down and it is one of the four major agricultural books in ancient China. Xin Qiji was born in Jin Guo, and his youth resisted Jin Guisong. He once served as the appeasement of Jiangxi and the appeasement of Fujian. He is the author of "The Ten Essays on the United States" and "The Nine Sessions". Due to dissatisfaction with the political and political parties, he was impeached and retired from the mountain. Before and after the opening of the Northern Expedition, they were successively used as the prefect of Shaoxing, the prefect of Zhenjiang, and the authority of the Central Committee. Three years after his reopening (1207), Xinjiu died of illness and he was sixty-eight years old. After the pursuit of young teachers, nicknamed "Zhongmin." The number of Southern Literature is three times that of the Northern Song Dynasty. Among them, Xin Qiji is the first of 629 first words. 


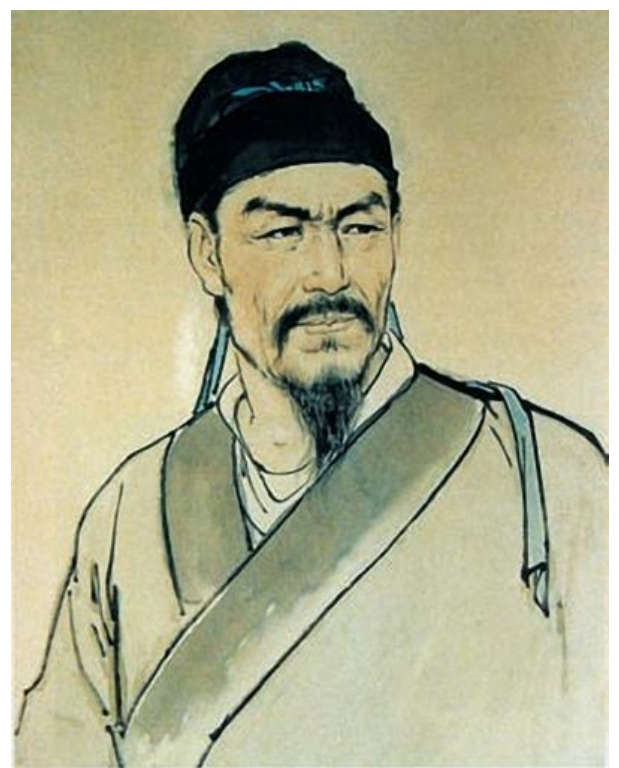

Fig. 3 Representatives of the poets of the Northern Song Dynasty -Xin Qiji

\section{Conclusion}

The dissemination of Song literature is a unique literary culture. The development and perfection of the Song dynasty literature produced a remarkable dissemination effect, which is inseparable from the influence of the mature literary form and its unique communication environment, mode of transmission, and power of communication. From the content point of view, based on popular words, since the Song Dynasty, communicators began to become a specialized cultural profession and dominated literary activities. The dissemination of literature is a social activity, with social politics, economy, and culture. The various elements in development and communication activities also produce corresponding changes. The status, role and importance of communication activities in the Song Dynasty are also different. The Song Dynasty literary works opened up a new field of literature research in the Song Dynasty, which promotes the direction of the Song Dynasty literary studies. Modernization undoubtedly has important and far-reaching influence and significance.

\section{Acknowledgments}

The paper is one of periodical findings of "Research of Shandong-Born Poets of River and Lake School in Southern Song Dynasty and Their Literature" which is a Humanities and Social Sciences Project in Colleges and Universities in Shandong Province. (Project No. J15WD48)

\section{References}

[1]. Wang Shaping, et al. Communication and acceptance: Two other dimensions of the study of literary history. Jiang Hay Due Boa. Vol. 36 (1998) No.12, p. 126-129.

[2]. Zhu Lidia. Xing Jajuan, et al. accepted the history of the Qing Dynasty. Jinan: Silo Publishing. Vol. 24 (2005) No.10, p. 215-221.

[3]. Li Dingdong, et al. "Flower Room Collection" accepts the history of the draft. Jinan: Silo Publishing House. Vol. 23 (2006) No.4, p. 39-43.

[4]. Qi and Dishing, et al. Tang and Song Dynasty word dissemination research. Shanghai: Furan University Press. Vol. 35 (2009) No.5, p.72-76.

[5]. Chen Suisun, et al. The spread and acceptance of Tang and Song $\mathrm{Cu}$ in the late Ming and early Qing Dynasty. Beijing: China Social Sciences Press. Vol. 19 (2010) No. 7, p.82-86. 
[6]. Tan Xenon, et al. Study on the transmission mode of song words. Wuhan: Wuhan University Press. Vol. 30 (2010) No. 12, p. 115-119.

[7]. Zhang Sailing, et al. Song Chi's acceptance of Bay Judi and its cultural interpretation. Chinese rhyme literary journal. Vol. 18 (2001) No. 9, p.362-369.

[8]. Zhang Sailing. Xing Fiji's, et al. Acceptance of Bay Judi: The 24th Series. Shanghai: East China Normal University Press. Vol. 16 (2010) No. 6, p. 136-142. 